\title{
ADAPTATION AND VALIDATION OF THE SCALES FOR ASSESSING WORKPLACE FUN IN TURKEY
}

\author{
DOI: 10.17261/Pressacademia.2021.1390 \\ RJBM- V.8-ISS.1-2021(2)-p.15-26
}

\author{
Wichakorn Sekarawisut ${ }^{1}$, E. Serra Yurtkoru ${ }^{2}$ \\ ${ }^{1}$ Marmara University, Faculty of Business Administration, 34722, Istanbul, Turkey. \\ wichakorn.sekarawisut@gmail.com, ORCID: 0000-0002-6315-7510 \\ ${ }^{2}$ Marmara University, Faculty of Business Administration, 34722, Istanbul, Turkey. \\ syurtkoru@marmara.edu.tr, ORCID: 0000-0002-9476-8445
}

\begin{tabular}{l}
\hline Date Received: January 14, $2021 \quad$ Date Accepted: March 25, 2021 \\
\hline To cite this document \\
Sekarawisut, W., Yurtkoru, E. S. (2021). Adaptation and validation of the scales for assessing workplace fun in Turkey. Research Journal of Business \\
and Management (RJBM), V.8(1), p.15-26. \\
Permanent link to this document: $\frac{\text { http://doi.org/10.17261/Pressacademia.2021.1390 }}{\text { B }}$ \\
Copyright: Published by PressAcademia and limited licensed re-use rights only.
\end{tabular}

\section{ABSTRACT}

Purpose - Fun in the workplace has frequently been highlighted in the popular media and increasingly attracted research attention. Its various positive outcomes have also been pointed out in the literature. Despite the growing relevance of workplace fun, its measurement has not been extensively tested, particularly in emerging markets. Accordingly, this study was intended to adapt and validate existing scales measuring different aspects of workplace fun in Turkey.

Methodology - Four measures of workplace fun, namely "fun activities", "fun job responsibilities", "coworker socializing" and "manager support for fun", were identified from the literature. These measures were translated and adapted for a Turkish sample. Their face validity and content validity were checked by experts in the field. Subsequently, the measures were tested on a sample of 254 employees working in startups in Turkey. The sample was randomly split into two groups for exploratory factor analysis and confirmatory factor analysis.

Findings - 24 items were derived from the literature. As expected, four factors were revealed in the exploratory factor analysis. One item was removed due to the insufficient factor loading on any factor. The reliability values of all factors were satisfactory. These results were confirmed in the confirmatory factor analysis, which showed that the measurement model had an acceptable fit to the sample data. In addition, the discriminant validity and the convergent validity were established.

Conclusion - The findings of this study suggested that the adapted version of the scales for measuring "fun job responsibilities", "fun activities", "manager support for fun", and "coworker socializing" can be used in Turkey. Researchers can employ these scales to examine the four dimensions of workplace fun as distinct constructs. Additionally, managers can utilize the validated indicators of workplace fun as a basis for creating a fun workplace.

Keywords: Workplace fun, fun activities, fun job responsibilities, coworker socializing, manager support for fun, startup JEL Codes: M10, M13, 015

\section{INTRODUCTION}

Fun in the workplace is increasingly becoming more relevant in today's business world. The fun work environment of many wellknown companies is frequently highlighted by the popular media. Google and Facebook are good examples. The East Coast headquarters of Google lets its employees have fun by providing several areas for playing, conference rooms decorated in a Broadway theme, areas for socialization that imitate vintage subway cars, standing desks equipped with treadmills, etc. (Stewart, 2013, March 15). The engineering office of Facebook in London is another example of offices that are designed to be a fun place. The employees there can play games with their coworkers in the games room and are offered a wide selection of meals and desserts for free (Tech Insider, 2018, December 19). These famous and fun companies have influenced many young companies, particularly startups. Indeed, workplace fun is now generally considered as part of the startup culture (Studholme, 2014). 
The relevance of fun in the workplace is not only recognized by the media and popular opinion. Many scholars are also interested in understanding what role fun plays in organizations. Academic research that has been done up to this time has suggested that fun benefits organizations in many different ways. For example, workplace fun was found to positively affect customer service quality (Karl \& Peluchette, 2006), job satisfaction (McDowell, 2004; Peluchette \& Karl, 2005), employee commitment (McDowell, 2004), employee performance (Fluegge, 2014), applicant attraction (Tews, Michel, \& Bartlett 2012) and job engagement (Müceldili \& Erdil, 2016). On the other hand, it was reported to be negatively related to emotional exhaustion (Karl, Peluchette, \& Harland, 2007) and turnover intention (Karl, Peluchette, \& Hall, 2008; McDowell, 2004; Tews, Michel, \& Stafford, 2013).

To quantitatively measure fun at work, researchers have taken different approaches. Karl, Peluchette and their colleagues operationalized it as an individual's perception of the existence of fun in the workplace and treated it as a single unidimensional construct (e.g. Karl \& Peluchette, 2006; Karl et al., 2008; Peluchette \& Karl, 2005). McDowell (2004) and Fluegge (2014) examined workplace fun as a multidimensional construct composed of "socializing with coworkers", "celebrating at work", "personal freedoms" and "global fun". However, both researchers aggregated the four dimensions of fun at work into a single measure.

Recently, Tews and his colleagues have directed research attention to the individual dimensions of workplace fun. Rather than combining those dimensions into one construct, they treated them as distinct constructs (e.g. Tews et al., 2012; Tews et al., 2013; Tews, Michel, \& Allen, 2014). In this way, they were able to assess the effect of each dimension of workplace fun on specific outcomes. Their studies revealed that different dimensions of workplace fun did not necessarily have the same effect. For instance, Tews et al. (2013) found that "manager support for fun" was negatively related to volunteers' turnover, whereas "fun activities" positively affected their performance. Their findings highlighted the importance of measuring the dimensions of workplace fun separately.

Although the measurements of workplace fun have been used in multiple studies, validation of these measurements in emerging markets is still lacking. In Turkey, they have not yet been extensively tested. This study was intended to fill this gap in existing research. To accomplish this objective, it drew on Michel, Tews and Allen's (2019) framework, which suggests four dimensions of workplace fun: "fun activities", "fun job responsibilities", "coworker socializing" and "manager support for fun". The scales measuring these dimensions of workplace fun were derived from the literature. Then, they were adapted and validated on a sample of employees working in startup companies in Turkey.

\section{DEFINITIONS OF WORKPLACE FUN}

Defining fun in the workplace is not as straightforward as it may seem. The definitions that exist in the literature contain some inconsistencies. One of them concerns the types of activities in which individuals can have fun. According to McDowell (2004), workplace fun are those activities "not specifically related to the job that are enjoyable, amusing, or playful (p. 9)". On the contrary, Fluegge (2008) defined workplace fun as "any social, interpersonal, or task activities at work of a playful or humorous nature which provide an individual with amusement, enjoyment, or pleasure (p. 15)". That is to say, fun task activities are excluded in McDowell's (2004) definition but are included in Fluegge's (2008) definition.

Another inconsistency in the definitions of workplace fun is related to how it happens. Ford, McLaughlin and Newstrom (2003) stated that a fun work environment "intentionally encourages, initiates, and supports a variety of enjoyable and pleasurable activities that positively impact the attitude and productivity of individuals and groups (p. 22)". For them, such activities include celebrations, social events, and competitions that the company organizes. However, according to Bolton and Houlihan (2009), these fun activities are just one form of workplace fun, which they termed "packaged fun" or "managed fun". They pointed out that there is another form of workplace fun, which is called "organic fun". This form of workplace fun inheres in the work that employees do rather than comes from those fun activities.

Michel et al. (2019) proposed a more inclusive definition of workplace fun by drawing on the literature pertaining fun in organizations. They defined workplace fun as "characteristics or features of the work environment of a social, playful, and humorous nature, which have potential to trigger positive feelings of enjoyment, amusement, and lighthearted pleasure in individuals (p. 99)". The present study was based on this definition as it incorporates the different aspects of fun in the workplace. Specifically, this study considered both work-related and non-work-related activities and both "managed fun" and "organic fun" as workplace fun.

To further clarify the meaning of workplace fun, it is important to also consider the definitions of other similar concepts. In the organization literature, fun, humor, and play are easily confused with one another due to their closeness in meaning, but there are some differences that differentiate them. Play in organizational contexts is defined as "an intrinsically motivated, fun activity, 
carried out recursively in the form of a practice, typically in the context of social relationships (Statler, Heracleous, \& Jacobs, 2011, p. 238)". According to this definition, play resembles fun since both of them involve enjoyable activities. Also, play has two forms that are analogous to "managed fun" and "organic fun". Mainemelis and Ronson (2006) posited that play can be manifested as a form of diversion from work tasks, which is similar to "managed fun", or as a form of engagement with those tasks, which is similar to "organic fun". Nevertheless, Michel, et al. (2019) argued that the concept of play in the workplace is more narrowly focused and is in fact a sub-component of workplace fun. To illustrate, play activities, such as competing in an office beer pong tournament and playing computer games with coworkers, are part of workplace fun. However, not all types of workplace fun are play. For example, company picnics and birthday celebrations are not considered as play.

Humor at work is defined as "any event shared by an agent (e.g. an employee) with another individual (i.e. a target) that is intended to be amusing to the target and that the target perceives as an intentional act (Cooper, 2005, pp. 766-767)". Cooper (2005) stated that humor could manifest itself in many forms, including verbal expressions, such as using sarcasms and making jokes, and non-verbal expressions, such as sharing humorous images or messages. Humor and fun at work are similar in the sense that both of them give a feeling of amusement. However, they are argued to be two different concepts. Michel, et al. (2019) pointed out that humor is one aspect of workplace fun and that workplace fun includes a wider range of activities and interactions that do not involve humor.

\section{COMPONENTS OF WORKPLACE FUN}

Researchers have offered different categorizations of workplace fun based on their perspectives and focuses. Some of them viewed workplace fun as a single construct and focused specifically on fun activities. This group of researchers includes Ford et al. (2003), who sought to identify activities that create a fun work environment. Based on a review of the related literature and a survey of human resource managers, they proposed ten categories: "celebrations", "employee recognition", "social events", "activities for relieving stress", "games", "community volunteerism", "opportunities for personal development", "friendly employee competition", "humor" and "entertainment (e.g. musical bands and theatrical plays)". These activities were reported to contribute to a fun work environment to different extents. Karl, Peluchette, Hall and Harland (2005) similarly based their categorization of fun activities at work on the literature and a survey. They suggested that there are eight types of fun activities: "outings", "food", "awards/prizes", "gifts", "contests", "games", "celebrations" and "wild and wacky (e.g. giving prizes for the most bold and unusual clothing and hula hoop races)". Chan (2010) took a grounded theory approach and identified four categories of fun activities: "staff-oriented workplace fun" (e.g. celebrations for birthdays and work anniversaries), "socialoriented workplace fun" (e.g. trips and parties organized by the company), "supervisor-oriented workplace fun" (e.g. informal gatherings and lunches with supervisors) and "strategy-oriented workplace fun" (e.g. food and refreshments provided by the company, sessions for asking top management questions).

Another group of researchers recognized that fun at work has dimensions other than fun activities but still treated it as a single construct. Among these researchers, McDowell (2004) offered a framework of workplace fun, which she developed based on a quantitative study. The framework consists of four dimensions: "socializing with coworkers", "personal freedoms", "celebrating at work" and "global fun". However, she combined these dimensions into an overall measure of workplace fun in her subsequent study of the effects of workplace fun on employees' affective commitment and turnover intention. Her framework was similarly used in other research. For example, in Fluegge's (2014) study of the relationships between workplace fun and performance outcomes, the four dimensions of workplace fun were aggregately examined.

There has been a call for researchers to study individual aspects of workplace fun instead of combining them into one single construct. Researchers who followed this call have developed different sets of dimensions of workplace fun and examined them as distinct constructs. Tews and his colleagues were the major contributors to the research in this stream. Their studies were focused on specific aspects of workplace fun. These include "fun coworker interactions", "formal fun activities" and "fun job responsibilities" in Tews et al. (2012); "manager support for fun" and "fun activities" in Tews et al. (2013); "manager support for fun", "fun activities" and "coworker socializing" in Tews et al. (2014); and "manager support for fun", "fun activities", "coworker socializing" and "fun job responsibilities" in Tews, Michel, Xu and Drost (2015). Tews and the co-authors also examined the relationships between the above dimensions of workplace fun and some outcomes and found that they had different effects. For example, "manager support for fun" was negatively related to "employee turnover" but had no impact on "employee performance", whereas "fun activities" had no relationship with "employee turnover" but positively affected "employee performance" (Tews et al., 2013). These findings highlighted the importance of investigating different aspects of workplace fun. 
More recently, Michel et al. (2019) has introduced a new framework, which incorporates the various aspects of workplace fun. From a review of the literature, they identified two main dimensions of workplace fun: "fun events" and "support for fun", which are composed of different sub-dimensions. The former includes "fun activities", "fun job responsibilities" and "coworker socializing", and the latter includes "manager support for fun" and "personal freedom". According to the authors, "personal freedoms" can be considered as part of "manager support for fun". Therefore, they might be combined into one construct.

\section{MEASURES OF WORKPLACE FUN}

The present study was based on Michel et al.'s (2019) framework. To be specific, it was focused on four dimensions of workplace fun, which were (1) "fun activities", (2) "fun job responsibilities", (3) "coworker socializing" and (4) "manager support for fun". The measures of these constructs were derived from the related literature. Subsequently, they were translated from English into Turkish and adapted for a Turkish sample. All of the measures were reviewed and confirmed for the face validity and content validity by academics who were experts in the field.

\subsection{Fun Activities}

Fun activities have been commonly accounted one of the main aspects of workplace fun and have been the focus of many studies pertaining fun in organization contexts. They are defined as "social and group activities initiated by the organization intended to promote enjoyment among employees (Tews et al., 2014, p. 928)". There is a wide range of activities that are considered as fun activities at work. Examples of these activities include parties, competitions, company outings, and celebrations. Much research effort has been devoted to identifying these activities and possible categorizations, which have subsequently been used as bases for developing scales measuring fun activities. Ford et al. (2003) were among the main contributors to this research stream. They focused their study on identifying activities that contributed to a fun work environment. Their findings, which suggested ten types of fun activities, were used in later quantitative studies. These include Tews et al.'s (2013) study, where a scale of fun activities was developed based on the previous study. The scale contained five items: "social events", "teambuilding activities", "competitions", "public celebrations of work" and "recognition of personal milestones". These items were tested on a sample of restaurant employees in the US. The Cronbach's alpha coefficient of .75 was reported. The same scale was also used on a similar sample in Tews et al.'s (2014) study, where the Cronbach's alpha coefficient was .76, and on a sample of employees in Turkey's service sector in Müceldili and Erdil's (2016) study, where the Cronbach's alpha coefficient was .85.

Another scale for measuring fun activities was developed by Karl et al. (2005). Unlike Tews et al.'s (2013) scale, this scale contains twenty-six items, which are categorized into eight types of fun activities: "awards/prizes", "contests", "games", "outings", "gifts", "food", "wide and wacky" and "celebration". In other words, each type of fun activities consists of more than one item. The fun activities that are included in the scale range from conventional ones, such as "celebrate employees' birthdays by bringing in cake and ice cream once a month" to less common ones, such as "start meetings by asking everyone to complete an open-ended sentence: "wouldn't it be fun if..." or "the funniest thing I've seen at work is..." (Karl et al., 2005, p. 7)". The scale was validated by using a sample of various occupations in different types of organizations, including non-profit organizations, public organizations and private organizations. The Cronbach's alpha coefficients were obtained for each type of fun activities, ranging from .69 to .93.

A measure of fun activities can also be found in McDowell's (2004) study. It is termed "celebrating at work" and is among the four dimensions of the fun climate scale, which measures the overall fun in the workplace. Similar to the previously mentioned fun activities scales, celebrating at work is composed of a list of fun activities. There are six items in total: "celebrations at work", "office parties", "company provided refreshments", "observing birthdays and other events", "festivities during holidays and other special times" and "throwing parties to recognize accomplishments". However, after the scale was tested on employees working in a private oil company in the US, one item, "company provided refreshments", was removed. The Cronbach's alpha coefficient of the five-item version of the scale was reported at .79. Tew et al. (2015) adopted this scale in their study. Based on a sample of employees in different organizational settings, the results showed a Cronbach's alpha value of 0.88 .

Following Tews et al. (2014) and Müceldili and Erdil (2016), this study used Tews et al.'s (2014) five-item scale for measuring the fun activities dimension of workplace fun. Respondents were asked to rate how frequently each fun activity happened. The items were rated along a six-point interval format continuum ranging from 1 (never) to 6 (always).

\subsection{Fun Job Responsibilities}

Fun job responsibilities are defined by Tew et al. (2012, p. 108) as "tasks that are personally enjoyable, meaningful, and a good fit to the person's interests." This dimension of workplace fun has received relatively small attention in research on fun in the workplace compared to other dimensions. It was argued that fun at work is not related to the work itself (McDowell, 2004). 
Nevertheless, some scholars regarded work-related fun as an aspect of workplace fun (e.g. Fluegge, 2014; Michel et al., 2019; Tew et al., 2015). Tew et al. (2012) conducted an experiment to examine the impact of fun job responsibilities and other aspects of workplace fun on companies' applicant attraction. In their study, participants were assigned to different scenarios where job responsibilities were presented as either fun or not fun. Building on this study, Tew et al. (2015) developed a four-item scale for measuring fun job responsibilities and tested it on employees in the US. They reported a Cronbach's alpha coefficient of 0.88 for the scale.

Although fun job responsibilities are seemingly overlooked in the workplace fun literature, the concept has been extensively examined in research on workaholism and work enthusiasm. Spence and Robbins (1992) stated that work enthusiasts find their job enjoyable, whereas workaholics have low enjoyment. They developed a scale called "work enjoyment" to measure the extent to which an individual finds their job responsibilities fun and enjoyable. According to the authors, this scale can be used to determine workaholism, work enthusiasm as well as other work-related profiles. The scale is composed of ten items and has been validated as a component of the workaholism battery along with "work involvement" and "drivenness" (e.g. Andreassen, Hetland, \& Pallesen, 2010, 2014; Ersoy-Kart, 2005; McMillan, Brady, O’Driscoll, \& Marsh, 2002; McMillan \& O’Driscoll; 2004).

In this study, Spence and Robbins's (1992) scale was used to assess fun job responsibilities together with three other dimensions of workplace fun. Respondents were asked to indicate how frequently each of the statements occurred by rating on an interval type scale ranging from 1 (never) to 6 (always).

\subsection{Coworker Socializing}

Coworker socializing refers to social interactions that are friendly and playful among employees (Michel et al., 2019). Such interactions include sharing personal stories with one another, hanging out together and exchanging jokes. Researchers commonly view coworker socializing as an aspect of workplace fun (e.g. Fluegge, 2014; McDowell, 2004; Tew et al., 2014) and generally use McDowell's (2004) measure of socializing with coworkers as a basis for measuring the construct. In Fluegge's (2014) study, all of the six original items were used. Based on a sample of working students in the US, the results showed a Cronbach's alpha coefficient of 0.85 . Tew and his colleagues adapted the original scale in their measurement of coworker socializing. In Tew et al.'s (2014) and Tew et al.'s (2015) studies, a four-item scale was used, and the Cronbach's alpha coefficients were reported at .83 and .90 , respectively. These results were also based on employees in the US. Recently, this adapted version of the scale has been used in Turkey by Müceldili and Erdil (2016), who reported a Cronbach's alpha coefficient of .86.

To be consistent with the previous study that was conducted in Turkey, the present study also used Tews et al.'s (2014) coworker socializing scale to assess the extent to which employees socialized with their coworkers. All items were scored on an interval type scale ranging from 1 (never) to 6 (always).

\subsection{Manager Support for Fun}

Manager support for fun is the extent to which managers allow and encourage subordinates to have fun at work (Tews et al., 2014). It was examined as a distinct construct in several studies concerning workplace fun (e.g. Karamfilov, 2018; Müceldili \& Erdil, 2016; Tews et al., 2014; Tews et al., 2015). However, in some other studies (e.g. Fluegge, 2014; McDowell, 2004), manager support for fun was treated as one of the items for assessing the overall fun in the workplace. To measure the manager support for fun construct, Tews et al. (2014) and Tews et al. (2015) used the same scale, which was adapted from Shanock and Eisenberger's (2006) measure of "supervisor support". The scale contains five items and the Cronbach's alpha coefficients in the two studies were reported at .92 and .94, respectively. This scale was also tested in Turkey by Müceldili \& Erdil (2016) and the Cronbach's alpha value in this study was .93. Another measure of manager support for fun was developed by Karamfilov (2018). It is a sevenitem scale modified from McDowell's (2004) fun climate scale to focus on leaders' endorsement of workplace fun, and was validated on a sample of employees in various industries in the US. The results indicated a Cronbach's alpha coefficient of 84.

It should be noted that manager support for fun is similar to personal freedom. Both constructs concern employees' opportunity to have fun. Thus, Michel et al. (2019) suggested that they can be combined into one construct. Nevertheless, past studies were generally focused on either of them. For example, McDowell (2004) and Fluegge (2014) studied personal freedom, whereas Tews et al. (2014) and Tews et al. (2014) chose manager support for fun.

In this study, manager support for fun was selected to be the focus and was measured by using Tews et al.'s (2014) five-item scale. Employees were asked to indicate how frequently each statement related to their managers happens by using an interval scale ranging from 1 (never) to 6 (always). 


\section{DATA AND METHODOLOGY}

The sample used in this study consisted of 254 employees working in startup companies in Turkey. A startup is defined as a "product focused private tech company with lots of blurry things like revenue model, customer, and product (Presidency of the Republic of Turkey Investment Office, 2019, p. 22)". In recent years, interest in building startup companies has significantly increased, especially in Turkey. Between 2013 and 2017, Turkey saw the highest number of newly registered startup companies among the countries in Europe (Tolentino, 2018, July 12). Startup culture has also received much attention. Startup companies are particularly known for their various "fun" benefits, such as unlimited free snacks, video games in the office and exciting team outings, which are used to attract talented candidates and motivate existing employees (Studholme, 2014). Given such characteristics, startup companies were deemed suitable for this study.

The respondents were obtained by using convenience sampling and their responses were collected through questionnaires. Two types of questionnaires were used: a self-administered paper-and-pencil questionnaire and a self-administered web-based questionnaire. These two questionnaires were composed of the same list of items arranged in the same order. The questionnaire items included the measures of "coworker socializing", "manager support for fun", "fun activities", "fun job responsibilities" and basic demographic information. All of the respondents were informed about the purpose of the study and the confidentiality and anonymity of their responses.

63 percent of the respondents were male and 37 percent were female. The average age of the respondents was 27 years with standard deviation of 4 years. 86 percent of them were single and 98 percent had completed a bachelor's degree or higher. All respondents were working on a full-time basis and the majority of them (60 percent) had been working in the company for less than one year. The average of their weekly working hours was approximately 49 hours. The respondents were in different departments; 40 percent were involved in programing and product development, 20 percent supported business clients or end users and the rest worked in various other areas, including marketing, human resources, accounting and sales.

Prior to analyses, the sample was randomly divided into two groups. The first group, which consisted of 131 respondents, was used in exploratory factor analyses (EFA) to identify the underlying patterns of the measurement scales of workplace fun. Varimax was used as the rotation method. Subsequently, to verify the validity of the structure obtained from the EFA, confirmatory factor analysis (CFA) was carried out on the second group of the sample, which comprised 123 respondents. Also, the convergent validity and discriminant validity were evaluated.

\section{FINDINDS}

\subsection{Exploratory Factor Analysis}

In order to identify the underlying patterns of the scales for measuring workplace fun, EFA was performed. Kaiser-Meyer-Olkin (KMO) measure of sampling adequacy was at a satisfactory level (.912) and Bartlett's test of sphericity was significant $\left(\chi^{2}=\right.$ $2279.80, \mathrm{df}=253, \mathrm{p}<.001)$. These results indicated that the data were appropriate for conducting factor analyses.

A principal components analysis with varimax rotation was carried out initially on 24 items. As expected, the analysis revealed four factors, which were called "fun activities", "fun job responsibilities", "coworker socializing" and "manager support for fun", in line with the literature. However, one item originally from the "fun job responsibilities" scale was eliminated because it did not load on any factor with a sufficiently large factor loading $(<.5)$.

Table 1 presents the results of the EFA. The cumulative percentage of the total variance accounted for by these four constructs was at an acceptable level (70.529 percent). The percentages explained by "fun job responsibilities", "fun activities", "manager support for fun" and "coworker socializing" were 24.398 percent, 16.571 percent, 16.516 percent and 13.044 percent, respectively. Cronbach's alpha reliability analyses were applied to measure the internal consistency of the constructs. The results were found to be above the acceptable threshold of .7 (Hair, Black, Babin, \& Anderson, 2014). "Fun job responsibilities" attained a value of .922; "fun activities", .877; "manager support for fun", .945; and "coworker socializing", .826. 
Table 1: Factor Loadings for Exploratory Factor Analysis (Varimax Rotation)

\begin{tabular}{|c|c|c|c|c|c|}
\hline & Item & 1 & 2 & 3 & 4 \\
\hline \multicolumn{6}{|c|}{ Fun job responsibilities } \\
\hline FR5 & "Most of the time my work is very pleasurable" & .802 & & & \\
\hline FR8 & "My job is more like fun than work" & .799 & & & \\
\hline FR6 & "Sometimes I enjoy my work so much I have a hard time stopping" & .783 & & & \\
\hline FR1 & "My job is so interesting that it often doesn't seem like work" & .782 & & & \\
\hline FR3 & "I lose track of time when I'm involved in a project" & .745 & & & \\
\hline FR4 & "I do more work than is expected of me strictly for the fun of it" & .737 & & & \\
\hline FR7 & "I like my work more than most people do" & .729 & & & \\
\hline FR2 & $\begin{array}{l}\text { "When I get involved in an interesting project it's hard to describe how } \\
\text { exhilarated I feel" }\end{array}$ & .715 & & & \\
\hline FR10 & $\begin{array}{l}\text { "Sometimes when I get up in the morning I can hardly wait to get to } \\
\text { work" }\end{array}$ & .712 & & & \\
\hline \multicolumn{6}{|c|}{ Fun activities } \\
\hline FA1 & "Public celebrations of work achievements" & & .841 & & \\
\hline FA4 & "Social events" & & .787 & & \\
\hline FA2 & "Team building activities" & & .739 & & \\
\hline FA5 & "Competitions" & & .643 & & \\
\hline FA3 & "Recognition of personal milestones" & & .587 & & \\
\hline \multicolumn{6}{|c|}{ Manager support for fun } \\
\hline MS4 & "My managers care about employees having fun on the job" & & & .840 & \\
\hline MS3 & "My managers try to make my work fun" & & & .815 & \\
\hline MS1 & "My managers encourage employees to have fun on the job" & & & .718 & \\
\hline MS2 & "My managers emphasize employee fun in the workplace" & & & .706 & \\
\hline MS5 & "My managers allow employees to play around on the job" & & & 636 & \\
\hline \multicolumn{6}{|c|}{ Coworker socializing } \\
\hline $\mathrm{CS} 2$ & "My coworkers and I joke around with each other" & & & & .839 \\
\hline CS1 & "My coworkers and I share stories with each other" & & & & .835 \\
\hline CS3 & "My coworkers and I socialize at work" & & & & .758 \\
\hline CS4 & "My coworkers and I socialize outside of work" & & & & 690 \\
\hline \multicolumn{2}{|c|}{ Eigenvalues } & 9.872 & 3.338 & 1.705 & 1.307 \\
\hline \multicolumn{2}{|c|}{$\%$ variance explained } & 24.398 & 16.571 & 16.516 & 13.044 \\
\hline \multicolumn{2}{|c|}{ Cronbach's alpha } & .922 & .877 & .945 & .826 \\
\hline
\end{tabular}

Note: Kaiser-Meyer-Olkin $(\mathrm{KMO})=.912$ and Bartlett's test of sphericity $<.001$.

\subsection{Confirmatory Factor Analysis}

To assess the validity of the structure obtained via the EFA, CFA was performed on a four-factor measurement model for "fun job responsibilities", "fun activities", "manager support for fun" and "coworker socializing". Figure 1 presents the output of the CFA model and table 2 summarizes the fit statistics. This study followed the model fit criteria recommended by Hair, et al. (2014). Specifically, the TLI and CFI values of greater than .90 and the RMSEA and SRMR values of lower than .08 were considered acceptable. The results showed that the chi-square statistic was statistically significant. While a significant chi-square may indicate a poor fit to the data, it is argued that it has some limitations, including the sensitivity to the model complexity and the sample size, and should not be a basis for rejecting a model (Schermelleh-Engel, Moosbrugger, \& Müller, 2003). The other model fit indices were as follows: the TLI value was .934, the RMSEA value was .066, the CFI value was .941 and the SRMR value was .061. According to the thresholds mentioned earlier, these values indicated an acceptable model fit. 
Figure 1: Measurement Model of Fun Job Responsibilities, Fun Activities, Manager Support for Fun and Coworker Socializing

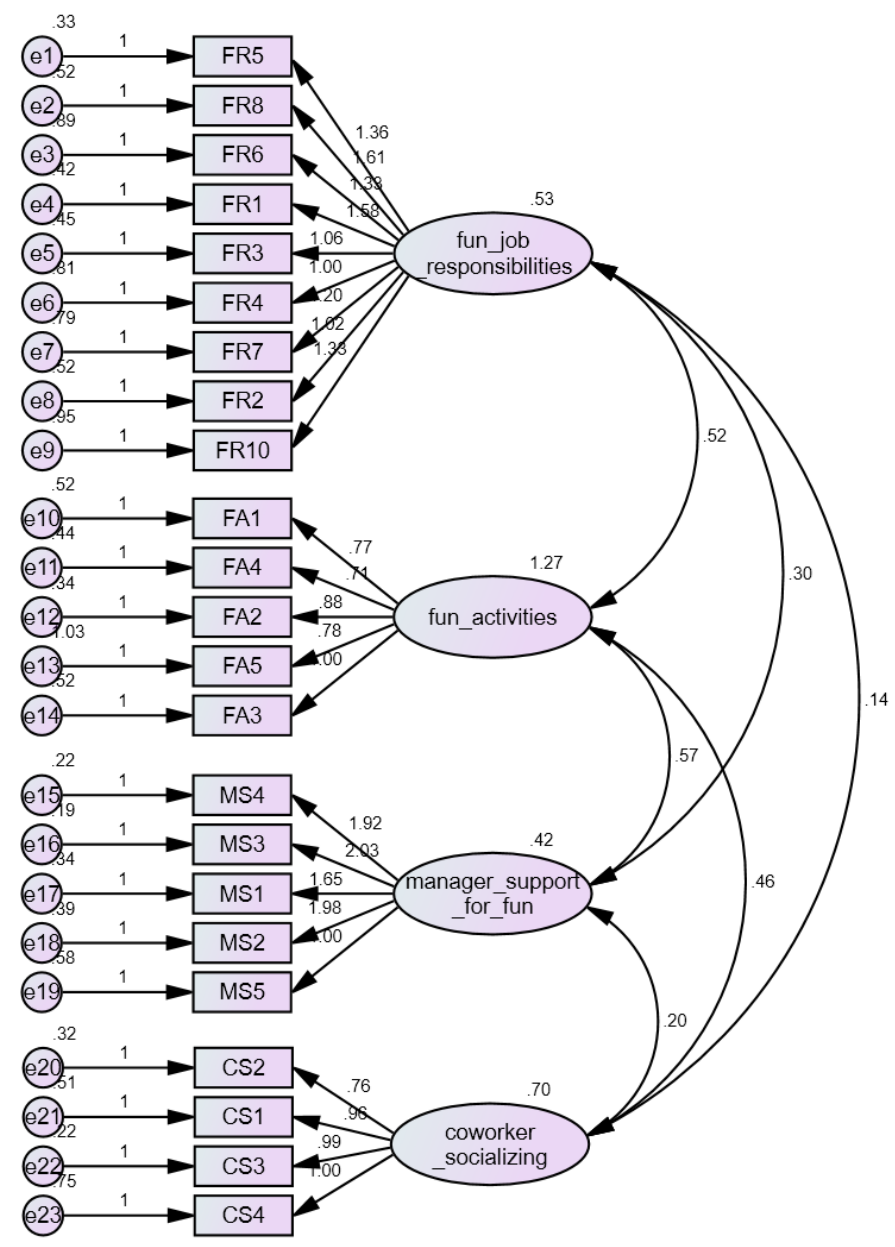

Table 2: Fit Statistics of Measurement Model

\begin{tabular}{ccccccc}
\hline$\chi^{2}$ & $\mathbf{d f}$ & $\boldsymbol{\chi}^{2} / \mathbf{d f}$ & TLI & RMSEA & CFI & SRMR \\
\hline $334.602^{*}$ & 224 & 1.494 & .934 & .066 & .941 & .061 \\
\hline Note* $*$ p $<.05$ & & & & & &
\end{tabular}

The unstandardized and standardized parameter estimates for "fun job responsibilities", "fun activities", "manager support for fun" and "coworker socializing" are shown in tables 3. As can be seen in the table, all of the indicators loaded on the underlying factors substantially with the factor loadings above the cut-off value of .50 (Hair, et al., 2014), ranging from .628 to .949. Since the model fit indices as well as the factor loadings demonstrated satisfactory results, any model respecification was not necessary. 
Table 3: Parameter Estimates and Cronbach's Alpha Coefficients of Fun Job Responsibilities, Fun Activities, Manager Support for Fun and Coworker Socializing

\begin{tabular}{|c|c|c|c|c|}
\hline Item & Unstandardized & C.R. & Standardized & Cronbach's alpha \\
\hline \multicolumn{2}{|c|}{ Fun job responsibilities } & & & .922 \\
\hline FR5 & 1.026 & 9.110 & .864 & \\
\hline FR8 & 1.211 & 8.983 & .852 & \\
\hline FR6 & .997 & 7.565 & .714 & \\
\hline FR1 & 1.186 & 9.166 & .870 & \\
\hline FR3 & .800 & 7.986 & .754 & \\
\hline FR4 & .752 & 6.670 & .628 & \\
\hline FR7 & .905 & 7.432 & .701 & \\
\hline FR2 & .768 & 7.607 & .718 & \\
\hline FR10 & 1.000 & - & .703 & \\
\hline \multicolumn{2}{|c|}{ Fun activities } & & & .880 \\
\hline FA1 & .769 & 9.876 & .769 & \\
\hline FA4 & .708 & 9.878 & .769 & \\
\hline FA2 & .877 & 11.716 & .862 & \\
\hline FA5 & .777 & 7.879 & .653 & \\
\hline FA3 & 1.000 & - & .843 & \\
\hline \multicolumn{2}{|c|}{ Manager support for fun } & & & .936 \\
\hline MS4 & 1.922 & 8.747 & .936 & \\
\hline MS3 & 2.035 & 8.830 & .949 & \\
\hline MS1 & 1.651 & 8.345 & .879 & \\
\hline MS2 & 1.984 & 8.492 & .899 & \\
\hline MS5 & 1.000 & - & .647 & \\
\hline \multicolumn{2}{|c|}{ Coworker socializing } & & & .841 \\
\hline CS2 & .758 & 7.329 & .745 & \\
\hline CS1 & .961 & 7.343 & .747 & \\
\hline CS3 & .994 & 8.150 & .870 & \\
\hline CS4 & 1.000 & - & .695 & \\
\hline
\end{tabular}

\subsection{Convergent and Discriminant Analyses}

To test the discriminant validity, the average variance extracted (AVE) analysis was carried out. In this analysis, if the square root of the AVE value of each individual latent construct is larger than its correlation with other latent constructs, the discriminant validity is confirmed (Zait \& Bertea, 2011). To assess the convergent validity, the AVE and the composite reliability, which indicate how well the indicators measure their latent construct, were examined. If the AVE value of the latent construct and its composite reliability value are greater than 0.5 and 0.6 respectively, the convergent validity can be established (Bagozzi \& Yi, 1988).

Table 4 shows the AVE, the construct reliability and the square root of the AVE for each construct, and the correlations among the four constructs. The AVE values of "fun job responsibilities" (.578), "fun activities" (.613), "manager support for fun" (.755) and "coworker socializing" (.588) were over the minimum threshold of .50, which confirmed the convergent validity. Their composite reliability values $(.924, .887, .938$ and .850 , respectively) were also found to be greater than the recommended threshold of .60. This indicated that the scales for the four constructs were reliable. These scales were further tested for the discriminant validity. As shown in table 4, the square roots of the AVE values for the four constructs, which are in the diagonal entries, were larger than their correlations, which are in the off-diagonal entries. These results confirmed the discriminant validity. 
Table 4: Results of Convergent and Discriminant Analyses

\begin{tabular}{|c|c|c|c|c|c|c|c|}
\hline Latent & CR & AVE & MSV & MS & FR & FA & CS \\
\hline MS & .938 & .755 & .608 & .869 & & & \\
\hline FR & .924 & .578 & .412 & .642 & .760 & & \\
\hline FA & .887 & .613 & .608 & .780 & .632 & .783 & \\
\hline $\mathrm{CS}$ & .850 & .588 & .239 & .368 & .235 & .489 & .767 \\
\hline
\end{tabular}

Note: MS: manager support for fun; FR: fun job responsibilities; FA: fun activities; CS: coworker socializing; CR: composite reliability; AVE: average variance extracted; MSV: maximum shared squared variance;

The numbers in bold denote the square root of the AVE and the other numbers indicate the correlation between variables.

\section{DISCUSSIONS AND CONCLUSION}

In the present study, the scales for measuring the four dimensions of workplace fun, namely "fun job responsibilities", "fun activities", "manager support for fun" and "coworker socializing", were adapted for the use in Turkey. These dimensions of workplace fun and their measurement scales were derived from the literature pertaining fun in the workplace. Subsequently, the scales were validated in the context of startups through EFA, CFA and other necessary analyses.

The results from EFA showed that 23 items loaded with sufficient factor loadings on the four dimensions of workplace fun as expected. Only one item, which was originally from the "fun job responsibilities" scale, did not sufficiently load on any dimension and hence was eliminated. Also, all of the scales were found to be reliable with the Cronbach's alpha coefficients of above .8. The structure obtained from the EFA was confirmed by the CFA results. The fit indices, including TLI, SMSEA, CFI and SRMR, indicated that the measurement model for the four constructs had an acceptable fit to the sample. The square root of every AVE for each construct exceeded the correlation of any pairs of constructs. This indicated the discriminant validity. Furthermore, the AVE and composite reliability values of over 0.5 and 0.6 respectively provided evidence for the convergent validity.

This study validated the measures of "fun job responsibilities", "fun activities", "manager support for fun" and "coworker socializing" with a sample of employees in startup companies in Turkey. By means of this, it provides an important contextual contribution to the literature on fun at work as past studies have not extensively validated these measures in this type of organizations or outside developed markets. Specifically, quantitative studies of workplace fun have been mostly conducted in established companies in the US (e.g. Fluegge, 2014; McDowell, 2004; Tews et al., 2014; Tews et al., 2015). This suggests that the measures of workplace fun can be used to assess the level of fun in startup companies in Turkey and may possibly be extended to studies in other contexts.

The theoretical contribution of this study is the inclusion of "fun job responsibilities" as another construct of workplace fun. This dimension of workplace fun has not been examined as much as the other dimensions. However, Michel et al. (2019) highlighted the importance of including "fun job responsibilities" in the model of workplace fun. Also, Tews et al. (2015) provided empirical evidence that "fun job responsibilities" were more effective in terms of enhancing job embeddedness. Thus, it is important for future research to include this construct when examining workplace fun.

As a methodological contribution, the confirmed discriminant validity of the measures suggested that there was sufficient difference among the four dimensions of workplace fun. This supports Michel et al.'s (2019) argument that "fun job responsibilities", "fun activities", "manager support for fun" and "coworker socializing" are theoretically and practically distinct and should not be combined into one single construct. The scales validated in this study can be used to examine these dimensions of workplace fun as individual constructs.

This study also has implications for practice. It suggests that founders, co-founders or managers who desire to create fun workplace should place importance on the different aspects of workplace fun and use the indicators this study confirmed as a basis for enhancing those fun aspects. Fun activities are particularly expected in start-up companies (Studholme, 2014). Managers may consider organizing fun activities of different types (i.e. celebrations of employees' achievements, recognition of their milestones, social events, competitions, and team building activities). To encourage socialization among employees, managers can provide dedicated areas and opportunities for them to socialize. Areas with playful themes in Google's headquarters (Stewart, 
2013, March 15) are practical examples. While freedom and fun are commonly incorporated in the culture of startup companies (Studholme, 2014), the leaders themselves still play a primary role in supporting or preventing fun (Karamfilov, 2018). Therefore, managers may also want to openly communicate their support for employees having fun in the workplace. Finally, enjoyable work can be created by matching employees with roles and tasks that they personally like and enjoy doing. If their interests and roles are mismatched, internal transition should be allowed.

However, some limitations should be noted. For one thing, the scales for measuring the four dimensions of workplace fun were validated on a sample of employees working in startup companies. The sample size was not large enough to test the invariance across different demographical characters. Future research may need to validate the scales in other types of organizations, for example, governmental organizations and large enterprises as well as different demographical groups, to confirm the results. For another thing, this study did not include "personal freedom" as a dimension of workplace fun due to its similarity with "manager support for fun" (Michel et al., 2019). However, future research may test them together to see whether they are perceived as different constructs.

\section{REFERENCES}

Andreassen, C. C., Hetland, J., \& Pallesen, S. (2010). The relationship between 'workaholism', basic needs satisfaction at work and personality. European Journal of Personality, 24(1), 3-17.

Andreassen, C. C., Hetland, J., \& Pallesen, S. (2014). Psychometric assessment of workaholism measures. Journal of Managerial Psychology, 29(1), 7-24.

Bagozzi, R., \& Yi, Y. (1988). On the evaluation of structure equation models. Journal of the Academy of Marketing Science, 16(1), 74-94.

Bolton, S. C., \& Houlihan, M. (2009). Are we having fun yet? A consideration of workplace fun and engagement. Employee Relations, 31(6), 556568.

Chan, S. C. H. (2010). Does workplace fun matter? Developing a useable typology of workplace fun in a qualitative study. International Journal of Hospitality Management, 29(4), 720-728.

Cooper, P. (2005). A study of innovators' experience of new product innovation in organizations. R\&D Management, 35(5), 525-533.

Ersoy-Kart, M. (2005). Reliability and validity of the workaholism battery (work-bat): Turkish Form. Social Behavior and Personality, 33(6), 609618.

Fluegge, E. R. (2008). Who put the fun in functional? Fun at work and its effects on job performance (Doctoral dissertation). Retrieved from https://ufdc.ufl.edu/UFE0021955/00001

Fluegge-Woolf, E. R. (2014). Play hard, work hard: Fun at work and job performance. Management Research Review, 37(8), 682-705.

Ford, R. C., McLaughlin, F. S., \& Newstrom, J. W. (2003). Questions and answers about fun at work. Human Resource Planning, 26(4), 18-33.

Hair, J. F., Black, W. C., Babin, B. J., \& Anderson, R. E. (2014). Multivariate Data Analysis (7th ed.). Essex, England: Pearson Education.

Karamfilov, K. (2018). Leader's endorsement of idiosyncratic workplace fun, organizational playfulness, climate, and organizational creativity (Doctoral dissertation). Retrieved from ProQuest.

Karl, K., \& Peluchette, J. (2006). How does workplace fun impact employee perceptions of customer service quality? Journal of Leadership and Organizational Studies, 13(2), 2-13.

Karl, K., Peluchette, J. V., \& Hall, L. M. (2008). Give them something to smile about: A marketing strategy for recruiting and retaining volunteers. Journal of Nonprofit \& Public Sector Marketing, 20(1), 71-96.

Karl, K., Peluchette, J., Hall, L., \& Harland, L. (2005). Attitudes toward workplace fun: A three sector comparison. Journal of Leadership and Organizational Studies, 12(2), 1-17.

Karl, K., Peluchette, J. V., \& Harland, L. (2007). Is fun for everyone? Personality differences in healthcare providers' attitudes toward fun. Journal of Human Health Services Administration, 29(4), 409-447.

Mainemelis, C., \& Ronson, S. (2006). Ideas are born in fields of play: Towards a theory of play and creativity in organizational settings. Research in Organizational Behavior, 27, 81-131.

McDowell, T. (2004). Fun at work: Scale development, confirmatory factor analysis, and links to organizational outcomes (Doctoral dissertation). Retrieved from ProQuest. 
McMillan, L. H. W., Brady, E. C., O’Driscoll, M. P., \& Marsh, N. V. (2002). A multifaceted validation study of Spence and Robbins' (1992) Workaholism Battery. Journal of Occupational and Organizational Psychology, 75(3), 357-368.

McMillan. L. H. W., \& O'Driscoll, M. P. (2004). Workaholism and health: Implications for organizations. Journal of Organizational Change Management, 17(5), 509-519.

Michel, J. W., Tews, M. J., \& Allen, D. G. (2019). Fun in the workplace: A review and expanded theoretical perspective. Human Resource Management Review, 29(1), 98-110.

Müceldili, B., \& Erdil, O. (2016). Finding Fun in Work: The effect of workplace fun on taking charge and job engagement. Procedia - Social and Behavioral Sciences, 235, 304-312.

Peluchette, J., \& Karl, K. A. (2005). Attitudes toward incorporating fun into the health care workplace. The Health Care Manager, 24(3), 268-275.

Presidency of the Republic of Turkey Investment Office. (2019). The State of Turkish Startup Ecosystem. Retrieved from https://di-digitalinnovation.s3.eu-central-1.amazonaws.com/di-bulten/files/Bulten+30/WEF_Top_10_Emerging_Technologies_2019_Report.pdf

Schermelleh-Engel, K., Moosbrugger, H. \& Müller, H. (2003). Evaluating the fit of structural equation models: Tests of significance and descriptive goodness-of-fit measures. Methods of Psychological Research, 8(2), 23-74.

Shanock, L. R., \& Eisenberger, R. (2006). When supervisors feel supported: Relationships with subordinates' perceived supervisor support, perceived organizational support, and performance. Journal of Applied Psychology, 91(3), 689-695.

Spence, J. T., \& Robbins, A. S. (1992). Workaholism: Definition, measurement, and preliminary results. Journal of Personality Assessment, 58(1), 160-178.

Statler, M., Heracleous, L., \& Jacobs, C. D. (2011). Serious play as practice of paradox. The Journal of Applied Behavioral Science, 47(2). 236-256.

Stewart, J. B. (2013, March 15). Looking for a lesson in Google's perks. The New York Times. Retrieved from https://www.nytimes.com/2013/03/16/business/at-google-a-place-to-work-and-play.html

Studholme, N. E. (2014). Silicon Valley Startup Companies: A question of culture (Senior thesis). Retrieved from https://scholarship.claremont.edu/cmc_theses/962

[Tech Insider]. (2018, December 19). Exclusive Look Inside Facebook's Engineering Office in London [Video file]. Retrieved from https://www.youtube.com/watch?v=VhuDhNLatlk

Tews, M. J., Michel, J. W., \& Allen, D. G. (2014). Fun and friends: The impact of workplace fun and constituent attachment on turnover in hospitality context. Human Relations, 67(8), 923-946.

Tews, M. J., Michel, J. W., \& Bartlett, A. (2012). The fundamental role of workplace fun in applicant attraction. Journal of Leadership \& Organizational Studies, 19(1), 105-114.

Tews, M. J., Michel, J. W., \& Stafford, K. (2013). Does fun pay? The impact of workplace fun on employee turnover and performance. Human Resources Management, 54(4), 370-382.

Tews, M. J., Michel, J., Xu, S., \& Drost, A. J. (2015). Workplace fun matters ... but what else? Employee Relations, 37(2), $248-267$.

Tolentino, C. (2018, July 12). Turkey has highest number of new startups registered in Europe. Travel Daily Media. Retrieved from https://www.traveldailymedia.com/turkey-most-startups-europe/

Zait, A., \& Bertea, P. E. (2011). Method for testing discriminant validity. Management \& Marketing, 9(2), $217-224$. 